\title{
Is Sjögren's syndrome a retroviral disease?
}

\author{
Nikolaos V Sipsas*, Maria N Gamaletsou and Haralampos M Moutsopoulos
}

\begin{abstract}
Circumstantial evidence suggests that retroviruses play a role in the pathogenesis of Sjögren's syndrome. Such evidence, derived from studies of patients with Sjögren's syndrome, includes the following: the presence of serum antibodies cross-reactive with retroviral Gag proteins; the occurrence of reverse transcriptase activity in salivary glands; the detection of retroviral antigens, retrovirus-like particles, or novel retroviral sequences in salivary glands; the occurrence of Sjögren's syndrome-like illnesses in patients having confirmed systematic infections with retroviruses such as human immunodeficiency virus-1 (HIV-1) and human T lymphotropic virus type 1; and the beneficial effect of anti-retroviral treatment on the occurrence of HIV-1-associated sicca syndrome. Additional evidence is provided by animal models.
\end{abstract}

\section{Introduction}

Sjögren's syndrome (SS) is a chronic disease affecting mainly the exocrine glands, but any organ or system of the body can be involved. SS can occur alone or in association with other autoimmune rheumatic diseases. A great deal of evidence supports the autoimmune nature of the disease: aggressive tissue infiltration by lymphocytes, a plethora of circulating autoantibodies, antibodies that cross the placenta and induce disease in the fetus, female preponderance, familial clustering with other autoimmune disorders, a strong association with specific human leukocyte antigen (HLA) alleles, and common clinical features with other autoimmune rheumatic diseases, such as arthritis, Raynaud phenomenon, and serositis [1]. Therefore, researchers characterized SS as autoimmune epithelitis [2].

SS is characterized by lymphocytic infiltration of the exocrine glands, such as salivary and lacrimal glands,

*Correspondence: nsipsas@med.uoa.gr

Pathophysiology Department, Laikon General Hospital and Medical School, National and Kapodistrian University of Athens, Mikras Asias 75, Athens - 11527, Greece where lymphocytes are not normally found. Lymphocytic infiltration leads to glandular dysfunction and the main clinical manifestations of SS (that is, oral and ocular dryness) (xerostomia and keratoconjunctivitis sicca). About 30\% of patients with primary SS develop extraglandular manifestations, including Raynaud phenomenon, peripheral neuropathy, vasculitis, hypergammaglobulinemic purpura, and hyperviscosity syndrome, as well as involvement of thyroid, lungs, kidneys, and liver. The worst outcome in a lymphocytic infiltrative disorder, such as SS, is the development of a lymphoproliferative disease, especially B-cell lymphoma, which occurs in approximately $5 \%$ of patients with SS. Anti-nuclear antibodies and various serum autoantibodies, such as antiSS-A (Ro) and SS-B (La) antibodies, are usually detected in patients with SS [1].

The pathogenesis of primary SS is a multi-factorial process leading to damage and dysfunction of the exocrine glands and other target organs. Environmental factors (such as a viral infection) affect the exocrine glands and stimulate dendritic or glandular cells to activate the HLA-independent 'innate immune system', which uses Toll and Toll-like receptors that recognize pathogen-specific epitopes. This process leads to upregulation of adhesion proteins and production of chemokines by the local epithelial cells, which become activated and act as antigen-presenting cells [3]. Lymphocytes migrate into the gland in response to chemokines, adhere to vascular adhesion molecules, and interact with dendritic and epithelial cells. Local production of cytokines, especially type I and type II interferons (IFNs), leads to perpetuation of the immune response and continuous stimulation of $\mathrm{T}$ and $\mathrm{B}$ cells, which may lead to gene mutations in B cells and lymphoma development. Overproduction of immunoglobulins, production of autoantibodies, and memory lymphocytes are also consequences of the aberrant activation of cellular immunity. Subsequent activation of tissue damage mechanisms, such as apoptosis, results in chronic inflammation of the affected glands, fibrosis, and loss of normal function [4].

Viruses can trigger autoimmune reactions in both humans and experimental animals through several mechanisms. The most important mechanisms are the virus-induced neoantigen expression, the molecular mimicry between viral and host antigens which results in 
the production of autoantibodies or cytotoxic T-cell clones (or both) targeting host tissues, and finally abnormalities in cytokine production which are caused by the viral infection. Although the etiology of SS is multifactorial, it appears that environmental factors trigger the syndrome in genetically predisposed individuals. Viral infections are the best candidates for the role of environmental triggers, and a number of observations support this notion [5]. For instance, the La/SSB antigen is increased in the nucleus, cytoplasm, and cell membrane of cells infected by viruses. The La antigen, a target of autoantibody production in SS, is involved in processing viral RNA. Similar increased concentrations were observed in acinic and conjunctival epithelial cells of patients with SS but not in healthy controls or patients with rheumatoid arthritis. Recent studies revealed a major role for activation of the type I IFN pathway in the pathogenesis of SS, as evidenced by the increased circulating type I IFN activity and an IFN 'signature' in peripheral blood mononuclear cells and minor salivary gland biopsies from these patients, a finding that further supports the idea of viral involvement in SS pathogenesis [6]. Early studies pointed to Epstein-Barr virus and cytomegalovirus as the triggering agents of SS. During the last decade, retroviruses [7] and enteroviruses [8] came into the spotlight.

Retroviruses are capable of infecting cells of the immune system, leading to destruction or stimulation of $\mathrm{T}$ cells, increased production of antibodies, and ultimately to heavy immunosuppression, making the patient vulnerable to opportunistic infections and malignancies, such as lymphomas. Several lines of epidemiological, serological, and experimental evidence have suggested that retroviral infections - especially those due to human T lymphotropic virus type 1, human immunodeficiency viruses (HIVs), human intracisternal A-type retroviral particle (HIAP-I), and human retrovirus-5 (HRV-5) - are implicated as the triggering factors for the development of SS (Table 1). The aim of this review is to summarize the existing data on the role of retroviruses in the etiopathogenesis of SS and delineate possible implications for the development of more effective treatment strategies.

\section{Human T lymphotropic virus type 1}

Human T lymphotropic virus type 1 (HTLV-1), the first human retrovirus to be discovered [9], causes two usually fatal diseases: adult T-cell leukemia/lymphoma [10] and HTLV-I-associated myelopathy (HAM) [11], the latter of which is also known as tropical spastic paraparesis. HTLV-1 is endemic in southern Japan, the Caribbean, South America, the Middle East, and southern Africa and is estimated to infect 10 to 20 million people worldwide [12]. Seroprevalence in endemic areas ranges from $3 \%$ to $5 \%$ in Trinidad and is as high as $30 \%$ in southern Japan [12].
In the '80s, an association between SS and HTLV-I infection was suggested by clinical reports and experimental data from murine animal models [5]. Initial clinical reports described some HTLV-I-infected patients who had tropical spastic paraparesis and who developed an SS-like illness [13]. Another report showed the presence of an antigen reactive with a monoclonal antibody to HTLV-I p19 in the minor salivary glands of patients with SS [14].

The possible association between HTLV-1 infection and SS, suggested by these initial observations, led to serological studies for the prevalence of antibodies to HTLV-I in patients with primary SS. In a study conducted in the Nagasaki Prefecture of Japan, which is endemic for HTLV-I infection, Eguchi and colleagues [15] examined serum samples from 36 consecutive patients with primary SS and found - by enzyme-linked immunosorbent assay, particle agglutination assay, and Western blotting - that $13(36 \%)$ were positive for antibodies to HTLV-I.

In another study, among 74 SS patients from the same area, the HTLV-1 seroprevalence rate was $23 \%$ (17/74), significantly higher than that among blood donors ( $3 \%$, or $916 / 27,284)$, whereas the difference between patients with systemic lupus erythematosus (SLE) and blood donors was insignificant. Salivary IgA antibodies to HTLV-1 were common among seropositive patients with SS (5/7), and this might be due to increased viral activity in the salivary glands. These antibodies were barely detectable in patients with HAM (prevalence of $1 / 10$ ) or in healthy carriers $(0 / 11)$ [16]. In response to the abovementioned report, Coulderc and colleagues [17] studied 11 patients who had primary SS and who were living in a non-endemic area (France), and detected anti-tax antibodies in 2 to 5 serum samples (depending on the technique), a finding suggesting that $\operatorname{tax}$ sequences of HTLV-1 might be implicated in the pathogenesis of SS. The detection of antibodies to HTLV-I proteins in SS patients from both endemic and non-endemic areas might suggest that other endogenous retroviruses are the etiological agents and that the occurrence of antibodies against HTLV-I is due to cross-reactivity between endogenous retroviral and HTLV-I proteins.

Sasaki and colleagues [18] examined the T-cell receptor (TCR) Vbeta gene usage by the infiltrating lymphocytes in the labial salivary glands (LSGs) from the HTLV-Iseropositive and HTLV-I-seronegative (idiopathic) patients with SS. The authors found accumulation of HTLV-Iinfected T cells expressing TCR with a conserved motif in both HTLV-I-associated and idiopathic SS [18]. In another study among HTLV-I-seropositive patients with SS, HTLV-I proviral DNA in the LSG was detected by polymerase chain reaction (PCR) and the localization of the viral DNA in the LSG was examined by in situ PCR hybridization [19]. The cellular DNA extracted from the 
Table 1. Studies providing evidence on the role of retroviruses in the pathogenesis of Sjögren's syndrome

\begin{tabular}{|c|c|c|c|}
\hline Retrovirus & Study & Origin & Main findings \\
\hline \multicolumn{4}{|l|}{ HTLV-1 } \\
\hline & [12] & USA & SS-like illness developed in HTLV-I-infected patients with tropical spastic paraparesis. \\
\hline & [13] & Europe & An antigen reactive with a monoclonal antibody to HTLV-I p19 was present in the LSG of patients with SS. \\
\hline & [14] & Japan & Thirty-six percent of patients with primary SS were found, by ELISA, to be positive for serum antibodies to HTLV-I. \\
\hline & {$[15]$} & Japan & $\begin{array}{l}\text { Rates of HTLV-1 seroprevalence were } 23 \%(17 / 74) \text { among patients with SS and } 3 \%(916 / 27,284) \text { among blood } \\
\text { donors. However, the difference between patients with systemic lupus erythematosus and blood donors was } \\
\text { insignificant. }\end{array}$ \\
\hline & [17] & Europe & Serum antibodies to HTLV-I were detected in 2 to 5 out of 11 patients with SS. \\
\hline & [18] & Japan & $\begin{array}{l}\text { HTLV-I-infected T cells expressing TCR with a conserved motif accumulated in both HTLV-I-associated and } \\
\text { idiopathic SS. }\end{array}$ \\
\hline & [19] & Japan & $\begin{array}{l}\text { HTLV-I proviral DNA was present in the nucleus of the infiltrating T cells but not in either the epithelial cells or the } \\
\text { acinar cells of the salivary glands of HTLV-I-seropositive patients with SS. }\end{array}$ \\
\hline & [20] & Japan & Definitive SS was diagnosed in 6 patients and probable SS in 2 patients among 10 patients with HAM. \\
\hline & {$[21]$} & Japan & Definite SS was diagnosed in 13 out of 20 patients with HAM. \\
\hline & [22] & Japan & $\begin{array}{l}\text { The HTLV-I tax gene, but not the HTLV-I gag, pol, or env genes, was detected in LSG samples from } 4 \text { out of } 14 \\
\text { patients with SS. }\end{array}$ \\
\hline & [23] & Europe & $\begin{array}{l}\text { The HTLV-I tax gene, but not the gag, pol, or env genes, was detected in LSG sections from } 2 \text { out of } 9 \text { patients } \\
\text { with SS and from none of the control subjects. }\end{array}$ \\
\hline & [24] & Europe & $\begin{array}{l}\text { The tax gene of HTLV-I was detected in LSG from } 15 \text { out of } 50 \text { of patients ( } 30 \%) \text { with SS, } 9 \text { out of } 32 \text { patients } \\
\text { ( } 28 \% \text { ) with other inflammatory processes ( } 3 / 9 \text { graft-versus-host disease, } 5 / 19 \text { extravasated cysts, and } \\
1 / 4 \text { sarcoidosis), and only } 1 \text { out of } 26 \text { patients ( } 4 \% \text { ) with normal LSG. }\end{array}$ \\
\hline & [25] & Japan & The HTLV-I tax gene was detected in LSG of 3 out of 17 seronegative patients (18\%) with SS. \\
\hline & {$[42]$} & USA & $\begin{array}{l}\text { An autoimmune exocrinopathy with histopathological findings similar to those of SS was observed in HTLV-1 tax } \\
\text { transgenic mice. }\end{array}$ \\
\hline
\end{tabular}

HIV-1

$\begin{array}{cll}{[27]} & \text { USA } & \text { An SS-like illness was reported among HIV-1-infected patients. } \\ {[28,29]} & \text { USA } & \text { The DILS was described as a disorder affecting a subgroup of patients with HIV-1 infection. } \\ {[30]} & \text { Europe } & \text { The prevalence of DILS among HIV-1-infected patients was } 7.79 \% . \\ {[31]} & \text { USA } & \text { The prevalence of DILS among HIV-1-infected patients was 32.3\%. } \\ {[32]} & \text { USA-Africa } & \begin{array}{l}\text { The prevalence of DILS in patients from the US was 6\%. The prevalence in patients with HIV infection from } \\ \text { Cameroon was 48\%. }\end{array} \\ {[33]} & \text { Europe } & \text { The prevalence of HIV-1-related SS dropped from 8\% in the pre-HAART era to 1.5\% in the post-HAART era. } \\ {[34]} & \text { USA } & \text { The prevalence of DILS dropped significantly in the post-HAART era. }\end{array}$

HIAP-I

[37] USA HIAP-I has been identified in lymphoblastoid cells cocultured with homogenates of salivary glands from patients with SS.

HRV -5
[40] Europe
Novel sequences spanning parts of the protease and reverse transcriptase open reading frames of a retrovirus were detected in LSG tissues of eight patients with SS.
[41] Europe
Two out of 55 LSG samples from patients with SS were positive for HRV-5 proviral DNA.

DILS, diffuse infiltrative lymphocytosis syndrome; ELISA, enzyme linked immunosorbent assay; HAART, highly active anti-retroviral treatment; HAM, HTLV-I (human T lymphotropic virus type 1)-associated myelopathy; HIAP-I, human intracisternal A-type retroviral particle; HIV-1, human immunodeficiency virus-1; HRV-5, human retrovirus-5; HTLV-1, human T lymphotropic virus type 1; LSG, labial salivary gland; SS, Sjögren's syndrome; TCR, T-cell receptor.

LSG contained full HTLV-I proviral DNA, which was present in the nucleus of the infiltrating $\mathrm{T}$ cells but not in the epithelial or the acinar cells of the salivary glands. Furthermore, the viral loads in the LSG were approximately 8 to $9 \times 10^{3}$ times higher than those in the peripheral blood mononuclear cells. These studies, taken together, support the hypothesis that HTLV-1-infected T lymphocytes infiltrate the salivary glands and initiate the pathogenetic mechanisms of SS.

The association of HTLV-1 with SS was indirectly shown in another Japanese study, which reported a high prevalence of SS in patients with HAM [20]. Ten 
consecutive patients with HAM were studied; according to the preliminary criteria for SS which were proposed by the European Community, definitive SS was diagnosed in 6 patients and probable SS was diagnosed in 2 patients. In a follow-up study from the same investigators, definite SS was diagnosed in 13 out of 20 patients with HAM [21].

Serological studies prompted the search for HTLV-1 genes in salivary glands of patients with SS. Two groups, one European and the other Japanese, have independently confirmed the presence of HTLV-I genome in salivary gland tissue from patients with SS [22,23]. In both cases, only the $\operatorname{tax}$ gene was detectable, whereas pol, gag, and env genes were not present. In the Japanese study, the HTLV-I tax gene, but not the HTLV-I gag, pol, or env genes, was detected in LSG samples from 4 out of 14 patients (29\%) [22]. Similarly, European investigators, using in situ hybridization and PCR, detected the tax gene, but not the gag, pol, or env genes, of HTLV-I in LSG sections from 2 out of 9 patients (22\%) with SS and from none of the control subjects [23]. In a follow-up study, the same group [24], using PCR, studied LSG tissues from 50 patients with definite SS and from 58 controls (32 patients with LSG associated with other inflammatory processes and 26 patients with normal LSG). The tax gene of HTLV-I was detected in LSG from 15 out of 50 patients (30\%) with SS but also in specimens from 9 out of 32 patients (28\%) with LSG involved by other inflammatory processes (3/9 graft-versus-host disease, $5 / 19$ extravasated cysts, and $1 / 4$ sarcoidosis) and from only 1 out of 26 patients (4\%) with normal LSG. A 652-base pair region, sequenced in 2 patients with SS, was $98 \%$ to $98.5 \%$ homologous to the canonic sequence of tax HTLV-I. Once more, HTLV-I gag, pol, and env genes were never detected. The findings of the European study support a non-specific role for the HTLV-1 $\operatorname{tax}$ gene in the pathogenesis of SS since low numbers of copies are detected also in other inflammatory processes.

Interestingly, in a report from Japan [25], an HTLV-I endemic area, HTLV-I tax sequence was detected in LSG of only 3 out of 17 seronegative patients (18\%) with SS, which is unexpectedly less frequent than in patients from Europe, which is an HTLV-I non-endemic area. Moreover, PCR revealed that the copy number of the HTLV-I tax in the gland tissue of these seronegative patients was very low and therefore unlikely to be sufficient to promote an inflammatory reaction in the tissue. These findings might argue against the involvement of HTLV-I in the pathogenesis of SS in Asian seronegative patients. The discrepancies between the European and Japanese studies suggest that HTLV-1, along with other environmental and genetic factors, might be a cofactor in the pathogenesis of SS.

It is possible that the failure to detect retroviral genes, other than tax, is the result of technical malfunctions or contamination issues. However, the similarity of the results deriving from two independent groups points to an alternative explanation: patients with SS were infected with a defective virus in which all genes, but tax, have been deleted. Defective HTLV-I proviruses have been shown to contribute to the pathogenesis of hematological malignant diseases, such as mycosis fungoides and HTLV-I-associated T-cell leukemia [26]. It is noteworthy that both studies, in contrast to the above-mentioned serological studies, failed to detect serum antibodies to HTLV-I in any of the studied patients with SS. The cause of this discrepancy is not clear; possibly, production of antibodies to HTLV-1 characterizes only a subgroup of patients with SS.

\section{Human immunodeficiency virus-1}

Early after the outbreak of the HIV epidemic, cases of an SS-like illness were reported among HIV-1-infected patients [27]. A few years later, the sicca syndrome associated with HIV-1 infection was defined as a discrete disease entity named diffuse infiltrative lymphocytosis syndrome (DILS) $[28,29]$. DILS, a disorder affecting a subgroup of patients with HIV-1 infection, is almost indistinguishable from SS, with bilateral parotid and lacrimal glandular swelling, xerostomia, and keratoconjunctivitis of varying intensity, frequently accompanied by persistent CD8 peripheral lymhocytosis and visceral infiltration by $\mathrm{CD} 8^{+} \mathrm{T}$ lymphocytes. This disorder differs from SS in that in the former the infiltrate in the salivary glands consists predominantly of $\mathrm{CD} 8^{+} \mathrm{T}$ cells (in contrast to primary SS, in which the infiltrate consists predominantly of $\mathrm{CD} 4^{+}$lymphocytes), anti-Ro and anti-La autoantibodies are seen less frequently, males are three times more likely to be infected [30], there are commonly numerous extraglandular manifestations such as lymphocytic pneumonitis, and there are different HLA associations (HLA-DR5 and DR6) [29]. The differences between DILS and SS might suggest different pathogenetic mechanisms. However, the predominantly $\mathrm{CD} 8^{+}$ infiltrates in DILS might be explained by the fact that HIV-1 infection is characterized by CD4 $4^{+}$lymphocytopenia and a relative $\mathrm{CD} 8^{+}$lymphocytosis. The excess of males in the Greek cohort of patients is also expected since the majority of HIV-1-infected patients in developed countries are males.

The prevalence of DILS among HIV-1-infected patients differs in published studies among different ethnic groups, a finding suggesting that HIV-1, along with genetic factors, might trigger the pathogenetic mechanisms of sicca. In a predominantly male, Greek cohort, the overall prevalence was $7.79 \%$, which is more than 2.5 times higher than that observed in normal Greek adult females [30]. In a larger cohort from the US, where different definitions and methodology were used, the 
prevalence of DILS was only 3\% [31]. In contrast, a histological study of minor salivary glands from 164 HIVpositive or -negative patients from Cameroon or the US showed a DILS prevalence of as high as $48 \%$ in patients with HIV infection from Cameroon but of only $6 \%$ in patients from the US. This striking difference was attributed to the fact that all African patients were treatment-naïve whereas $76 \%$ of American HIV-positive patients had received anti-retroviral therapy [32].

These data underline the impact of highly active antiretroviral treatment (HAART) on the prevalence of DILS. A successful HAART reduces viral replication, viral load in the peripheral blood falls to undetectable levels, the number of $\mathrm{CD}^{+} \mathrm{T}$ lymphocytes increases, and finally reconstitution of the immune system occurs. In a followup study, the prevalence of HIV-1-related SS dropped from $8 \%$ in the pre-HAART era to $1.5 \%$ (2 out of 131 patients) after the introduction of HAART [33]. Similar data were reported in a study from the US, where the prevalence of DILS had dropped significantly in the postHAART era [34]. This beneficial effect of HAART on the prevalence of DILS is indirect evidence that HIV-1 contributes to the pathogenesis of the HIV-1-associated sicca. If the virus per se infects the salivary glands triggering the pathogenetic mechanisms, it is quite logical that inhibition of viral replication and reduction of viral load lead to a reduction in the prevalence of DILS. However, a researcher from Italy reported that, in a cohort of 150 HIV-1-infected patients, 4 developed an SS-like illness, with positive salivary gland biopsy, 6 to 48 months after initiation of HAART [35]. In other words, an SS-like syndrome was rather a complication of HAART. These contradictory data on the effect of HAART might reflect the complexity of the pathogenetic mechanisms involved in the sicca syndrome associated with HIV-1 infection.

\section{Other retroviruses}

The presence of a syndrome resembling SS in a subgroup of patients with HIV-1 infection was another indirect piece of evidence that retroviruses might be the triggering environmental factor for the development of SS. Therefore, there was an effort to detect antibodies to retroviral proteins or retroviral antigens or both in HIVnegative patients with primary SS. In a pivotal study, Talal and colleagues [7] performed immunoblotting against HIV-1 proteins by using sera from 47 HIV-1seronegative patients with primary SS. Moderate-tostrong reactivity, suggesting the presence of serum antibodies, was found in 14 patients (30\%). Of 120 normal subjects, only 1 showed moderate positivity. All 14 positive SS sera reacted against p24 (gag), which is a group-specific protein, but failed to react against gp41 or gp120 (env). Interestingly, only 1 of the 14 sera reacted against Ro (SS-A), and 1 other reacted against La (SS-B). These data suggest the presence of a subgroup of SS patients who resemble patients with HIV-1-induced SSlike disease. It should be noted that, in a subsequent study, serum antibodies to the p24 gag protein of HIV-1 were detected in 22 out of 61 patients (36\%) with SLE, a finding suggesting that reactivity to retroviral proteins is a phenomenon not specific to SS [36].

The reactivity of SS sera against only a group-specific antigen of HIV-1 raised the possibility that the retrovirus implicated in the pathogenesis of SS was not HIV-1 per se but an HIV-1-like retrovirus. Garry and colleagues [37] reported that an HIAP-I that is antigenically related to HIV-1 has been identified in lymphoblastoid cells cocultured with homogenates of salivary glands from patients with SS. HIAP-I shares a limited number of antigenic epitopes with HIV-1 but is distinguishable by morphological, physical, and biochemical criteria. A second type of human intracisternal A-type retrovirus, HIAP-II, was detected in a subset of patients with idiopathic CD4 lymphocytopenia (ICL), an AIDS-like immunodeficiency disease [38]. Most patients with HIAP-II-positive ICL were also antinuclear antibody-positive.

A subsequent report showed that sections of the minor salivary glands from $31 \%$ of patients with primary SS contained an epithelial cytoplasmic protein reactive with a monoclonal antibody to the $\mathrm{p} 19$ group-specific antigen (gag) of HTLV-1 [14]. Serum antibodies to HTLV-1 were negative, confirming that the antigen was not part of HTLV-1. The antigen showed properties consistent with an endogenous retrovirus in that it was absent in healthy tissues or resting cells.

Similar results were reported in a study from Japan, where retroviruses were sought in LSGs and peripheral blood mononuclear cells from patients with SS by immunoblotting assay, immunohistochemical assay, PCR, reverse transcriptase (RT) activity assay, and transmission electron microscopy [39]. Sera from 5 out of 15 patients (33\%) with SS reacted against the p24 (gag) antigen of HIV-1. LSG biopsy specimens from 7 of the 15 patients (47\%) with SS contained an epithelial cytoplasmic protein reactive with a monoclonal antibody to the p24 antigen of HIV-1. RT activity was detected in the salivary gland tissues in 3 out of 10 patients. Transmission electron microscopy revealed the presence of A-type-like retroviral particle epithelial cells of salivary glands. These data suggested the presence of an unknown retrovirus that is similar to HIV-1 in the salivary gland and that might be involved in the pathogenesis of SS in a subpopulation of patients with SS.

Another group, using a PCR-based strategy, detected novel sequences spanning parts of the protease and RT open reading frames of a retrovirus in salivary gland 
tissue of eight patients with SS [40]. The sequence is related to that of type $B$ and type $D$ retroviruses and was present in a sucrose density gradient fraction corresponding to that of an enveloped retrovirus particle. The researchers suggested that the sequence represents an infectiously acquired genome, provisionally called HRV-5. However, a follow-up study failed to show an association of HRV-5 infection with SS [41]. Out of 55 salivary gland samples from SS patients tested by nested PCR, only 2 were positive for HRV-5 proviral DNA. One possible explanation could be that, owing to the extremely low virus load in minor salivary glands, the number of HRV5-infected patients may be underestimated.

\section{Animal models}

An autoimmune exocrinopathy with histopathological findings similar to those of SS was observed in HTLV-1 $\operatorname{tax}$ transgenic mice [42]. After the insertion of the tax gene, the animals develop a spontaneous sialadenitis characterized by focal proliferation of ductal epithelial cells within the major and minor salivary glands followed by lymphocytic infiltration. A direct association between the expression of $\operatorname{tax}$ protein and the extent of the histological damage of the salivary glands was noticed. In another animal model, exocrinopathy resembling SS was induced in mice injected intraperitoneally with another murine retrovirus, the LP-BM5 murine leukemia virus [43].

\section{Therapeutic implications}

Steinfeld and colleagues, on the basis of the accumulating evidence for a role for retroviruses in the pathogenesis of SS as well as the clinical observation that the administration of zidovudine (AZT) in some patients with DILS led to diminution of parotid gland enlargement and overall improvement of sicca symptoms [44], undertook an open-label study evaluating the efficacy of AZT in seven patients with primary SS [45]. AZT, the first anti-retroviral agent to be approved for the treatment of HIV-1 infection, is a thymidine analog that reduces viral replication by inhibiting the viral RT. Treatment resulted in significant improvement in all subjective manifestations as well as the objective parameters of ocular dryness. The clinical benefit persisted in 5 out of 7 patients 1 month after the end of therapy [45]. Owing to the possible placebo effect, a common bias in open-label studies of drugs in primary SS, the results of this study should be interpreted with caution.

On the basis of these promising preliminary data, Gescuk and colleagues [46] conducted a placebo-controlled, randomized, double-blind study of lamivudine in primary SS. Lamivudine is a synthetic nucleoside RT inhibitor that inhibits replication of human retroviruses.
Sixteen patients with primary SS were randomly assigned to receive either lamivudine $150 \mathrm{mg}$ twice daily or placebo for 3 months. Treatment with lamivudine did not result in significant improvement in the primary outcome measure of unstimulated whole salivary flow or other secondary measures, including minor salivary gland biopsy focus scores. However, the study enrolled small numbers of subjects and thus might not have been powered to detect subtle differences.

The contradictory results for these two RT inhibitors may be due to the fact that retroviral infections can be treated effectively not with a single agent but with a combination of active anti-retroviral agents. The fact that the prevalence of DILS has been reduced significantly in the post-HAART era [33,34] points in this direction.

\section{Conclusions and future directions}

Circumstantial evidence suggests that retroviruses are candidates for the initiation or maintenance of autoimmunity in SS. Such evidence includes the presence of antibodies that are cross-reactive with retroviral Gag proteins in patients with SS, the detection of retroviral antigens in patients with SS, the isolation of retroviruslike particles or novel retroviral sequences from salivary glands of patients with SS, the occurrence of SS-like illnesses in patients having confirmed infections with known retroviruses such as HIV-1 and HTLV-1, the beneficial effect of HAART on the occurrence of HIV-1associated sicca syndrome, and the occurrence of RT activity in salivary glands of patients with SS. Additional evidence is provided by animal models; HTLV-1 tax transgenic mice develop sieladenitis characterized by lymphocytic infiltration.

On the other hand, serum antibodies that are crossreactive with retroviral Gag proteins have been described in other autoimmune diseases, such as SLE. None of the patients with SS has signs or symptoms of a systematic viral infection and there is no evidence for vertical or sexual transmission of a virus in patients with SS, all of which are characteristics of well-known retroviral diseases such as HIV-1 or HTLV-1 infection. The hypothesis that the culprit is a defective retrovirus, not able to cause systematic disease or to be transmitted, remains to be proven.

In conclusion, existing evidence suggests that retroviruses, along with other environmental and genetic factors, might play a pathogenetic role in a subpopulation of patients with SS. Future research should better define and characterize this subpopulation, delineate the implicated pathogenetic mechanisms, develop new diagnostic tools to accurately recognize patients with retrovirusassociated SS, and design new therapeutic approaches, possibly using combinations of newer anti-retroviral agents. 


Autoimmune Basis of Rheumatic Diseases
This article is part of a series on Sjögren's syndrome, edited by Thomas
Dörner, which can be found online at http://arthritis-research.com/
series/Sjögrens
This series forms part of a special collection of reviews covering major
autoimmune rheumatic diseases, available at:
http://arthritis-research.com/series/abrd

\section{Abbreviations}

AZT, zidovudine; DILS, diffuse infiltrative lymphocytosis syndrome; HAART, highly active anti-retroviral treatment; HAM, HTLV-I (human T lymphotropic virus type 1)-associated myelopathy; HIAP-I, human intracisternal A-type retroviral particle; HIV-1, human immunodeficiency virus-1; HLA, human leukocyte antigen; HRV-5, human retrovirus-5; HTLV-1, human T lymphotropic virus type 1; ICL, idiopathic CD4 lymphocytopenia; IFN, interferon; LSG, labial salivary gland; $P C R$, polymerase chain reaction; RT, reverse transcriptase; SLE, systemic lupus erythematosus; SS, Sjögren's syndrome; TCR, T-cell receptor.

\section{Competing interests}

The authors declare that they have no competing interests.

\section{Acknowledgments}

NVS acknowledges financial support from the Special Account for Research Funds (ELKE) of the National and Kapodistrian University of Athens, Greece.

Published: 13 April 2011

\section{References}

1. Sipsas NV, Tzioufas AG, Moutsopoulos HM: Sjögren's syndrome. Giorn /t Allergol Immunol Clin 1994, 4:181-190.

2. Moutsopoulos HM: Sjögren's syndrome or autoimmune epithelitis? Clin Rev Allergy Immunol 2007, 32:199-200.

3. Mitsias DI, Kapsogeorgou EK, Moutsopoulos HM: The role of epithelial cells in the initiation and perpetuation of autoimmune lesions: lessons from Sjögren's syndrome (autoimmune epithelitis). Lupus 2006, 15:255-261.

4. Katsifis GE, Moutsopoulos NM, Wahl SM: T lymphocytes in Sjögren's syndrome: contributors to and regulators of pathophysiology. Clin Rev Allergy Immunol 2007, 32:252-264.

5. Moutsopoulos HM, Papadopoulos GK: Possible viral implication in the pathogenesis of Sjögren's syndrome. Eur J Med 1992, 4:219-223.

6. Mavragani CP, Crow MK: Activation of the type I interferon pathway in primary Sjögren's syndrome. J Autoimmun 2010, 35:225-231.

7. Talal N, Dauphinee MJ, Dang H, Alexander SS, Hart DJ, Garry RF: Detection of serum autoantibodies to retroviral proteins in patients with primary Sjögren's syndrome (autoimmune exicrinopathy). Arthritis Rheum 1990, 33:774-781.

8. Triantafyllopoulou A, Moutsopoulos HM: Autoimmunity and coxsackievirus infection in primary Sjögren's syndrome. Ann N Y Acad Sci 2005, 1050:389-396.

9. Poiesz BJ, Ruscetti, FW, Gazdar, AF, Bunn PA, Minna JD, Gallo RC: Detection and isolation of type $C$ retrovirus particles from fresh and cultured lymphocytes of a patient with cutaneous T-cell lymphoma. Proc Nat/ Acad SciUSA 1980, 77:7415.

10. Yoshida M, Miyoshi I, Hinuma Y: Isolation and characterization of retrovirus from cell lines of human adult T-cell leukemia and its implication in the disease. Proc Natl Acad Sci U S A 1982, 79:2031.

11. Osame M, Usuku K, Izumo S, ljichi N, Amitani H, Igata A, Matsumoto M, Tara M: HTLV-1 associated myelopathy, a new clinical entity. Lancet 1986, 1:1031.

12. de Thé G, Bomford R: An HTLV-1 vaccine: why, how and for whom? AIDS Res Hum Retroviruses 1993, 9:381.

13. Vernant JC, Buisson G, Magdeleine J, de Thore J, Jouannelle A, NeissonVernant C, Monplaisir N: T-Lymphocyte alveolitis, tropical spastic paresis, and Sjögren's syndrome. Lancet 1988, 1:177.

14. Shattles WR, Brookes SM, Venables PJW, Clark DA, Maini RN: Expression of antigen reactive with a monoclonal antibody to HTLV-1 p19 in salivary glands in Sjögren's syndrome. Clin Exp Immunol 1992, 89:46-51.
15. Eguchi K, Matsuoka N, Ida H, Nakashima M, Sakai M, Sakito S, Kawakami A, Terada K, Shimada H, Kawabe Y: Primary Sjögren's syndrome with antibodies to HTLV-I: clinical and laboratory features. Ann Rheum Dis 1992, 51:769-776.

16. Terada K, Katamine S, Eguchi K, Moriuchi R, Kita M, Shimada H, Yamashita I, Iwata K, Tsuji Y, Nagataki S: Prevalence of serum and salivary antibodies to HTLV-I in Sjögren's syndrome. Lancet 1994, 344:1116-1119.

17. Coulderc L, Desgranges C, Coste J, Caubarrere I, Clauvel JP: Antibodies to HTLV-I in Sjögren's syndrome. Lancet 1995, 345:72.

18. Sasaki M, Nakamura S, Ohyama Y, Shinohara M, Ezaki I, Hara H, Kadena T, Kishihara K, Yamamoto K, Nomoto K, Shirasuna K: Accumulation of common T cell clonotypes in the salivary glands of patients with human $T$ lymphotropic virus type l-associated and idiopathic Sjögren's syndrome. J Immunol 2000, 164:2823-2831.

19. Ohyama Y, Nakamura S, Hara H, Shinohara M, Sasaki M, Ikebe-Hiroki A, Mouri T, Tsunawaki S, Abe K, Shirasuna K, Nomoto K: Accumulation of human T lymphotropic virus type l-infected T cells in the salivary glands of patients with human T lymphotropic virus type l-associated Sjögren's syndrome. Arthritis Rheum 1998, 41:1972-1978.

20. Nakamura H, Eguchi K, Nakamura T, Mizokami A, Shirabe S, Kawakami A, Matsuoka N, Migita K, Kawabe Y, Nagataki S: High prevalence of Sjögren's syndrome in patients with HTLV-I associated myelopathy. Ann Rheum Dis 1997, 56:167-172.

21. Nakamura H, Atsushi Kawakami, Masahiro Tominaga, Ayumi Hida, Satoshi Yamasaki, Kiyoshi Migita, Yojiro Kawabe, Tatsufumi Nakamura, Katsum Eguchi: Relationship between Sjögren's syndrome and human Tlymphotropic virus type I infection: Follow-up study of 83 patients. J Lab Clin Med 2000, 135:139-144.

22. Sumida, T, Yonaha, F, Maeda, T, Kita Y, Iwamoto I, Koike T, Yoshida S: Expression of sequences homologous to HTLV-1 tax gene in the labial salivary glands of Japanese patients with Sjögren's syndrome. Arthritis Rheum 1994, 37:545.

23. Mariette X, Agbalika, F, Daniel MT, Bisson M, Lagrange P, Brouet JC, Morinet F: Detection of human T lymphotropic virus type 1 tax gene in salivary gland epithelium from two patients with Sjögren's syndrome. Arthritis Rheum 1993, 36:1423.

24. Mariette X, Agbalika F, Zucker-Franklin D, Clerc D, Janin A, Cherot P, Brouet JC: Detection of the tax gene of HTLV-I in labial salivary glands from patients with Sjögren's syndrome and other diseases of the oral cavity. Clin Exp Rheumatol 2000, 18:341-347.

25. Mizokami A, Eguchi K, Moriuchi R, Futsuki Y, Terada K, Nakamura H, Miyamoto T, Katamine S: Low copy numbers of human T-cell lymphotropic virus type I (HTLV-I) tax-like DNA detected in the salivary gland of seronegative patients with Sjögren's syndrome in an HTLV-I endemic area. Scand J Rheumatol 1998, 27:435-440.

26. Tamiya S, Matsuoka M, Etoh K, Watanabe T, Kamihira S, Yamaguchi K, Takatsuki K: Two types of defective human T-lymphotropic virus type I provirus in adult Tcell leukemia. Blood 1996, 88:3065-3073.

27. Ulirsch RC, Jaffe ES: Sjögren's syndrome-like illness associated with the acquired immunodeficiency syndrome-related complex. Hum Patho/ 1987, 18:1063-1068.

28. Itescu S, Brancato LJ, Winchester R: A sicca syndrome in HIV infection: association with HLA-DR5 and CD8 lymphocytosis. Lancet 1989, 2:466-468.

29. Itescu S, Brancato LJ, Buxbaum J, Gregersen PK, Rizk CC, Croxson TS, Solomon $G E$, Winchester R: A diffuse infiltrative CD8 lymphocytosis syndrome in human immunodeficiency virus (HIV) infection: a host immune response associated with HLA-DR5. Ann Intern Med 1990, 112:3-10.

30. Kordossis T, Paikos S, Aroni K, Kitsanta P, Dimitrakopoulos A, Kavouklis E, Alevizou V, Kyriaki P, Skopouli FN, Moutsopoulos HM: Prevalence of Sjögren's-like syndrome in a cohort of HIV-1-positive patients: descriptive pathology and immunopathology. Br J Rheumatol 1998, 37:691-695.

31. Williams FM, Cohen PR, Jumshyd J, Reveille JD: Prevalence of the diffuse infiltrative lymphocytosis syndrome among human immunodeficiency virus type 1-positive outpatients. Arthritis Rheum 1998, 41:863-868.

32. McArthur CP, Africa CW, Castellani WJ, Luangjamekorn NJ, McLaughlin M, Subtil-DeOliveira A, Cobb C, Howard P, Gustafson S, Palmer D, Miranda RN: Salivary gland disease in HIV/AIDS and primary Sjögren's syndrome: analysis of collagen I distribution and histopathology in American and African patients. J Oral Pathol Med 2003, 32:544-551.

33. Panayiotakopoulos GD, Aroni K, Kyriaki D, Paikos S, Vouyioukas N, Vlachos A, Kontos AN, Kordossis T: Paucity of Sjögren's -like syndrome in a cohort of HIV-1-positive patients in the HAART era. Part II. Rheumatology (Oxford) 
2003, 42:1164-1167.

34. Basu D, Williams FM, Ahn CW, Reveille JD: Changing spectrum of the diffuse infiltrative lymphocytosis syndrome. Arthritis Rheum 2006, 55:466-472.

35. Mastroianni A: Emergence of Sjögren's syndrome in AIDS patients during highly active antiretroviral therapy. AIDS 2004, 18:1349-1352.

36. Talal N, Garry RF, Schur PH, Alexander S, Dauphinée MJ, Livas IH, Ballester A, Takei M, Dang H: A conserved idiotype and antibodies to retroviral proteins in systemic lupus erythematosus. J Clin Invest 1990, 85:1866-1871.

37. Garry RF, Fermin CD, Hart DJ, Alexander SS, Donebower LA, Luo-Zang H: Detection of a human intracisternal A-type retroviral particle antigenically related to HIV. Science 1990, 250:1127-1129.

38. Sander DM, Szabo S, Gallaher WR, Deas JE, Thompson JJ, Cao Y, Luo-Zhang H, Liu LG, Colmegna I, Koehler J, Espinoza LR, Alexander SS, Hart DJ, Tom DM, Fermin CD, Jaspan JJ, Kulakosky PC, Tenenbaum SA, Wilson RB, Garry RF: Involvement of human intracisternal A-type retroviral particles in autoimmunity. Microsc Res Tech 2005, 68:222-234.

39. Yamano S, Renard JN, Mizuno F, Narita Y, Uchida Y, Higashiyama H, Sakurai H, Saito I: Retrovirus in salivary glands from patients with Sjögren's syndrome. J Clin Pathol 1997, 50:223-230.

40. Griffiths DJ, Venables PJ, Weiss RA, Boyd MT: A novel exogenous retrovirus sequence identified in humans. J Virol 1997, 71:2866-2872.
41. Rigby SP, Griffiths DJ, Weiss RA, Venables PJ: Human retrovirus-5 proviral DNA is rarely detected in salivary gland biopsy tissues from patients with Sjögren's syndrome. Arthritis Rheum 1997, 40:2016-2021.

42. Green JB, Hinricks SH, Vogen J, Jay G: Exocrinopathy resembling Sjögren's syndrome in HTLV-I tax transgenic mice. Nature 1989, 341:72-74.

43. Suzuki K, Makino M, Okada Y, Kinoshita J, Yui R, Kanazawa H, Asakura H, Fujiwara M, Mizuochi T, Komuro K: Exocrinopathy resembling Sjögren's syndrome induced by a murine retrovirus. Lab Invest 1993, 69:430-435

44. Itescu S, Winchester R: Diffuse infiltrative lymphocytosis syndrome: a disorder occurring in human immunodeficiency virus-1 infection that may present as a sicca syndrome. Rheum Dis Clin North Am 1992, 18:683-697.

45. Steinfeld SD, Demols P, Van Vooren JP, Cogan E, Appelboom T: Zidovudine in primary Sjögren's syndrome. Rheumatology (Oxford) 1999, 38:814-817.

46. Gescuk B, Wu AJ, Whitcher JP, Daniels TE, Lund S, Fye K, Davis JC Jr:. Lamivudine is not effective in primary Sjögren's syndrome. Ann Rheum Dis 2005, 64:1326-1330.

doi:10.1186/ar3262

Cite this article as: Sipsas NV, et al.: Is Sjögren's syndrome a retroviral disease? Arthritis Research \& Therapy 2011, 13:212. 